Check for updates

London

Cite this as: BMJ 2020;369:m2310 http://dx.doi.org/10.1136/bmj.m2310 Published: 10 June 2020

\section{Covid-19: Better data on outbreaks will help control infection, say experts}

\author{
Shaun Griffin
}

Registered deaths mentioning covid-19 in England and Wales are continuing to decline, with 1822 deaths in the week ending 29 May, 767 fewer than the previous week, show figures from the Office for National Statistics. ${ }^{1}$

However, the covid-19 death rate is declining slowly and has a "long tail," reflecting ongoing issues in care homes and SARS-CoV circulating in hospitals, said Carl Heneghan, director of the Centre for Evidence Based Medicine at the University of Oxford.

At a Science Media Centre briefing on 9 June he said that, to support testing and tracking efforts, the Care Quality Commission and Public Health England should learn from Northern Ireland, where data are provided on active outbreaks of covid-19 in care homes and when these are resolved. ${ }^{2}$

\section{Closing outbreaks down}

The concept of "closing down" covid-19 infections in confined spaces, such as care homes, is incredibly important, Heneghan said, noting that around half of care homes in Northern Ireland had managed to do so. He called on the Care Quality Commission and Public Health England to provide equivalent data, as "it would be incredibly useful to have this information to support a test and trace system ... as part of quarantine and isolation.”

Northern Ireland's healthcare system is similar in size and structure to the old strategic health authorities in England, raising the question of whether it would be better to control this pandemic regionally, said Heneghan.

"Active infections should be taken seriously and managed in a coordinated way," he said, adding that it "makes sense to divert testing to areas where we have the outbreaks."

Citing the "extraordinary effort" made in the successful campaign to control MRSA, David Spiegelhalter, chair of the Winton Centre for Risk and Evidence Communication at the University of Cambridge, said that "a change in perspective to infection control ... seems very appropriate at this stage of the epidemic."

\section{Age effects}

Of deaths registered in England and Wales from 28 March to 29 May, covid-19 deaths added around 50\% to people's "normal" risk, Spiegelhalter calculated, with "increasing age dramatically adding to the risk." People aged over 45 have a 50\% increased risk of dying with covid, compared with a $20 \%$ increase in people aged 15-45 and a 2\% increase in 5-14 year olds.

He said, "The age gradient of dying with covid is staggering. Each five or six years you get older doubles your risk of dying with covid over the epidemic period," adding that, when multiplied by additional frailties in the older population, it became a "very unfortunate combination ... The 15000 additional excess deaths that have not been labelled as covid [involve] a mixture of under-diagnosis, particularly in the frail and elderly, and effects of disruption in the health service.”

With his colleague Harry Giles, Spiegelhalter also announced a new interactive tool showing the number of weekly covid and non-covid deaths in local authorities in England and Wales. ${ }^{3}$ Areas with many covid-19 deaths in hospitals in the nine weeks from 28 March include Birmingham, Leeds, Liverpool, and Brent in London, the data showed.

High numbers of covid-19 deaths in care homes were registered in County Durham and Sheffield, and Islington in London registered more than five times the expected number over this period. In Newham, another London borough, the number of registered deaths at home was more than three times higher than expected.

\section{Office for National Statistics. Deaths registered weekly in England and Wales, provisional: week ending 29 May 2020. 9 Jun 2020. https://www.ons.gov.uk/peoplepopulationandcommunity/birthsdeathsand- marriages/deaths/bulletins/deathsregisteredweeklyinenglandandwalespro- visional/weekending29may2020. \\ 2 Northern Ireland Statistics and Research Agency. Department of Health daily dashboard. https://app.powerbi.com/view?r=eyjrljoiZGYXNjYzNmU- tOTImZSO0ODAXLWE1YTEtMjAONjZhMzlmN2/mliwidCI6ljjOWEZMGRIL- WQ4ZDctNGFhNC05NjAwLTRiZTc2MjVmZjZjNSIsImMiOjh9. \\ 3 Winton Centre for Risk and Evidence Communication. Covid-19 deaths by local authority in England and Wales. https://wintoncen- tre.maths.cam.ac.uk/coronavirus/covid-excess/.}

This article is made freely available for use in accordance with BMJ's website terms and conditions for the duration of the covid-19 pandemic or until otherwise determined by BMJ. You may use, download and print the article for any lawful, non-commercial purpose (including text and data mining) provided that all copyright notices and trade marks are retained. 